\title{
A mediação da informação como prática pedagógica no contexto da biblioteca escolar: algumas considerações
}

\author{
Mediation of information as a pedagogical practice in the context of the school library: some \\ considerations
}

\begin{abstract}
Jonathas Luiz Carvalho Silva Mestre em Ciência da Informação pela Universidade Federal da Paraíba - UFPB. Doutorando em Ciência da Informação pela Universidade Federal da Bahia - UFBA. Professor do curso de Biblioteconomia da Universidade Federal do Ceará - Campus Cariri. E-mail: jonathascarvalhos@yahoo.com.br
\end{abstract} Andreia Santos Ribeiro Silva
Mestranda do Programa de pós-graduação em Ciência da Informação pela UFBA. Bibliotecária do Instituto
Federal de Educação, Ciência e Tecnológia da Bahia - IFBAHIA.
E-mail: asribeiro2001@ @yahoo.com.br

\section{Resumo}

Apresenta como objetivo investigar as perspectivas de aplicação da mediação da informação no âmbito da biblioteca escolar contemplando a realidade pedagógica, organizacional e dos serviços desenvolvidos, a partir da mediação implícita e explícita apresentada por Almeida Júnior (2009). Partindo dessas percepções o presente estudo estabelece perspectivas de mediação da informação na biblioteca escolar, objetivando contemplar a realidade pedagógica da mediação a luz de teóricos como Piaget (1978), Vygotsky (1998) e Freire (1978), organizacional com Vergueiro (1989) e dos serviços desenvolvidos nas bibliotecas escolares com Figueiredo (1996). Evidencia que a mediação da informação contribui para a biblioteca escolar como uma atribuição pedagógica e também em outros aspectos convergentes e/ou divergentes. Conclui que a mediação da informação na biblioteca escolar é um importante instrumento para a prática pedagógica, tanto no contexto implícito (sinalização, formação e desenvolvimento do acervo e organização/representação da informação), quanto no contexto explícito (mediação para leitura, pesquisa e serviços de referência, informação utilitária, além do uso das tecnologias digitais).

Palavras-chave: Mediação da informação. Biblioteca escolar. Mediação explícita. Mediação implícita.

\begin{abstract}
Its objective is to investigate the prospects for mediation of information within the school library contemplating the reality of pedagogical, organizational and services developed from the implicit and explicit mediation by Almeida Júnior (2009). Based on these insights this study provides prospects for mediation of information in the school library, aiming to address the pedagogical reality of mediation light of theorists such as Piaget (1978), Vygotsky (1998) and Freire (1978), organizational Vergueiro (1989) and services developed in school libraries to Figueiredo (1996). Evidence that the mediation of information contributes to the school library as a teaching award and also in other aspects of convergent and/or divergent. Concluded that the mediation of information in the school library is an important tool for teaching practice, both within implicit (signage, training and development of the organization and / representation of information), as in the explicit context (mediation for reading, research and services reference, information utility, and the use of digital technologies).
\end{abstract}

Keywords: Mediation of information. School library. Mediation explicit. Mediation implied. 


\section{Introdução}

Os estudos sobre mediação vem ganhando espaço na área de Ciência da Informação associado e aplicados a diversos contextos teóricos e empíricos e outros processos de informação, como a organização/representação, acesso, recuperação, uso e apropriação da informação, além de sua contiguidade com as tecnologias digitais, o que pode ser conferido a partir do status de ligação e interação da mediação, enquanto modus operandi.

Consideramos que os estudos sobre mediação se configuram, pelo menos de forma parcial, a partir de uma interligação/intersecção entre informação e comunicação (GOMES, 2010a), o que permite a sua aplicação em diversos contextos culturais e sociais. Essa aproximação entre comunicação e informação no âmbito da mediação favorece a possibilidade de valorizar estudos sobre mediação da informação em centros de informação, como a biblioteca universitária, pública e no próprio ciberespaço. Percebemos que, embora ocorra um crescimento dos estudos de mediação em centros de informação, ainda é muito tímido os estudos de mediação em bibliotecas escolares.

Essa timidez pode ocorrer em face da desvalorização acadêmico-profissional que tem sido conferida a biblioteca escolar, embora não possamos deixar de reconhecer que realidade vem melhorando em face de algumas conquistas políticas, como a lei 12.244/10, pois conforme Carvalho Silva (2011, p. 511) “a Lei 12244/10 mostra uma conotação de mudança, pois se configura precisamente na possibilidade de transformações que a biblioteca escolar precisa para mostrar sua potencialidade".

Entendemos que a mediação da informação e a biblioteca escolar pensadas de forma coletiva podem promover um conjunto de contribuições para a comunidade escolar valorizando a construção social do conhecimento, assim como valorizando as questões sociais e interacionistas que norteiam o acesso e uso da informação. Por isso, acreditamos que a mediação da informação pode ser expressada de muitas formas no âmbito das bibliotecas, inclusive a escolar, dependendo dos contextos sociais e cotidiano das comunidades que estão inseridas.

Assim, o presente trabalho tem como condição problematizadora uma questão que pode ser discutida a partir da seguinte pergunta: como pode ser pensada e aplicada a mediação da informação em bibliotecas escolares considerando as perspectivas da mediação implícita e explícita? O estudo tem como objetivo geral investigar as perspectivas de aplicação da 
mediação da informação no âmbito da biblioteca escolar contemplando a realidade pedagógica, organizacional e dos serviços desenvolvidos. Os objetivos específicos são: a) conceber uma reflexão sobre o termo mediação da informação; e b) analisar a mediação como fundamento de prática pedagógica.

\section{Reflexões sobre mediação da informação: entre o conceito e a aplicação}

A mediação da informação tem se configurado como um efetivo instrumento para reflexões e estudos no campo da Ciência da Informação (CI). É pertinente atentar para o conceito de mediação da informação basicamente por dois motivos gerais:

a) O conceito mediação prima pela ausência de um consenso com relação ao conceito de mediação, o que permite inferir que até hoje não foi sujeito a um exercício de apropriação e ajustamento pelos especialistas em CI e, quando usado por estes, foi como cópia ou tradução direta de certas fontes. (MALHEIRO; RIBEIRO, 2011, p. $155)$;

b) Por ser, a mediação da informação um processo de transição e/ou articulação entre a produção, circulação e a apreensão da informação, aproximando emissor e receptor; serviço e usuário; profissional e usuário.

De acordo com Almeida Júnior (2009, p. 92) a mediação da informação significa “Toda ação de interferência - realizada pelo profissional da informação -, direta ou indireta; consciente ou inconsciente; singular ou plural; individual ou coletiva; que propicia a apropriação de informação que satisfaça, plena ou parcialmente, uma necessidade informacional."

Isso significa dizer que a mediação da informação inclui dois fatores fundamentais: a apropriação da informação que é inerente ao processo de produção/disseminação da informação e interferência que é inerente aos procedimentos de como a informação será destinada ao usuário.

Desse modo, compreender a mediação da informação fundamenta os pressupostos que dão vazão a três percepções: processos, fluxos e comportamentos informacionais, pois a mediação da informação será vital para entender como a informação é produzida, assim como os comportamentos informacionais envolvidos. 
Isso implica afirmar que a mediação é fruto de um propósito que envolve todo o processo informacional no âmbito das redes sociais e humanas no uso da informação, de sorte que a informação utilizada nas redes indica diversas propostas de mediação informacional na concepção triádica emissor-canal-receptor, além dos diversos problemas e desafios para mediação da informação em redes sociais e humanas; e competências informacionais e programas de inclusão digital, visto que a mediação da informação, através do conhecimento da produção informacional e da apreensão pelo usuário, pode identificar pontos deficitários e qualitativos que interferem ou favorecem as competências em informação, inclusive no que tange a informação digital.

De forma mais intensa refletir sobre a mediação da informação deságua naturalmente no discurso de Gomes (2010b, p. 87) quando afirma que "para tratar de mediação, de início, é preciso situá-la como ação vinculada à vida, ao movimento, ao processo de construção de sentidos."

Isso significa dizer que a mediação da informação é uma atividade que está essencialmente inserida no cotidiano, seja social (indivíduos, grupos ou comunidades), seja institucional (bibliotecas, arquivos, museus, empresas, etc.) se constituindo como fundamento social de ação e interação. Em outras palavras, a mediação da informação é construída por meio do diálogo com o ser (usuário) com vistas à satisfação de determinadas necessidades/finalidades informacionais.

Para tanto, conforme nos revela Almeida Júnior (2009, p. 92-93) a mediação pode ser envidada a partir de uma perspectiva implícita e explícita:

A primeira, a mediação implícita, ocorre nos espaços dos equipamentos
informacionais em que as ações são desenvolvidas sem a presença física e imediata
dos usuários. Nesses espaços, como já observado, estão a seleção, o armazenamento
e o processamento da informação. A mediação explícita, por seu lado, ocorre nos
espaços em que a presença do usuário é inevitável, é condição sine qua non para sua
existência, mesmo que tal presença não seja física, como, por exemplo, nos acessos
a distância em que não é solicitada a interferência concreta e presencial do
profissional da informação.

Destarte, compreendemos que a mediação da informação é um instrumento que está intrinsecamente ligado a outros processos de informação, como, de um lado, a organização e representação da informação e, de outro lado, o acesso, uso, apreensão e apropriação da informação. A mediação da informação age como um fio condutor que liga processos e aproxima construtos de processamentos técnicos aos procedimentos de ação social e pedagógica. 


\section{0 alarido da mediação: fundamento de prática pedagógica}

A mediação como prática pedagógica pode ser pensada em diversos contextos. De modo gera, para este estudo, 1 é possível pensar a mediação como prática pedagógica em dois contextos, a saber: primeiro é o teórico-metodológico que contempla, por exemplo, o construtivismo (PIAGET; GARCIA, 1987), a teoria sócio-histórica (VYGOTSKY, 1998) e a mediatização de Paulo Freire (1987); e o segundo é o processo empírico-contextual sendo possível destacar, de forma macro, a mediação a partir de instrumentos como a escola, a universidade, etc. e, de forma micro, a mediação por meio do professor, da sala de aula, da biblioteca, entre outros.

Atribuindo como ponto central de reflexão o contexto teórico-metodológico é pertinente conceber um arrazoado das três concepções supramencionadas. Iniciando pelo construtivismo tem suas fundamentações baseadas na Psicologia e, mais precisamente, no pensamento de Piaget. O construtivismo é uma teoria que visa reconhecer que as idéias e o conhecimento não são fatores acabados, mas permanentemente interpretados e amadurecidos.

Para embasar a teoria construtivista Piaget (1978) partiu de duas perguntas cruciais: como se passa de um conhecimento elementar, insuficiente, para um conhecimento superior? Como desenvolvem os conhecimentos, considerando sua formação na infância até chegar ao pensamento adulto e ao conhecimento científico?

Por isso que diante das perguntas é comum observar a ênfase do olhar piagetiano para o público infantil, de sorte que contempla uma perspectiva promissora de estudos psicossociais que permite pensar a mediação do conhecimento a partir de uma concepção perspectivo-construtiva desde a fase da infância até a fase adulta.

Quanto a teoria sócio-histórica quando Vygostsky começa a pensá-la está inserido no contexto da revolução soviética de 1917 e, por conseguinte, dos ideários marxistas, o que instiga a promover a idéia de que o ser é constituído pelas relações sociais e não simplesmente pelos contextos da mente. Na teoria de Vygostsky, alguns termos são centrais, tais como: história, cultura, sujeito (ser) e interação.

Destarte, na visão de Vygotsky (1998) a interação que promove a constituição do sujeito é baseada em tudo aquilo que esteve anteriormente no âmbito social. Isso significa dizer que a partir do movimento da internalização, o sujeito se apropria do que existe no meio 
externo através da mediação de signos apropriados na relação com outros para promover a internalização.

Com efeito, a mediação tem influência efetiva para construção da teoria sóciohistórica, de modo que atua como elo entre o domínio social/histórico-cultural e as construções de conceitos, apropriações e aprendizagens do sujeito, o que culmina com o que Vygotisky (1998) chamou de Funções Psicológicas Superiores (FSP). A relevância da mediação na teoria sócio-histórica no âmbito das funções psicológicas superiores pode ser enfatizada no discurso de Vygotsky (1998, p. 73) quando afirma que:

(...) O uso de meios artificiais - a transição para a atividade mediada - muda, fundamentalmente, todas as operações psicológicas, assim como o uso de instrumentos amplia de forma ilimitada a gama de atividades em cujo interior as novas funções psicológicas podem operar. Nesse contexto, podemos usar o termo função psicológica superior, ou comportamento superior com referência à combinação entre o instrumento e o signo na atividade psicológica.

Vygostky reconhece que a mediação interfere ou modifica as operações psicológicas ampliando e amadurecendo as atividades históricas, culturais, sociais e psicológicas do ser, o que implica dizer que a combinação entre o instrumento mediado e o resultado promovido na atividade psicológica do ser concebe uma função psicológica superior ou comportamento superior. Em suma, a mediação na teoria sócio-histórica de Vygostsky contribui nos processos de apropriação e aprendizagem do ser por meio das interações e internalizações.

Com relação a percepção em Paulo Freire denominada de mediatização, percebemos que o educador em questão estabelece uma relação direta entre o ser e a educação, sendo mediatizada pela realidade social que o cerca. Todavia, essa mediatização não prima pela arbitrariedade, mas busca na contradição uma superação dialética que permita a autonomia do ser.

Freire (1987, p. 68) confirma o pensamento do parágrafo anterior quando afirma que "ninguém educa ninguém, ninguém educa a si mesmo, os homens se educam entre si, mediatizados pelo mundo". Outrossim, observamos que a autonomia do ser deve primar pelo respeito, pelo reconhecimento dos processos de opressão intelectual, abstrativa e/ou material, visando efetivar sua superação, o que sustenta uma emancipação ou libertação do ser diante da realidade que o oprime. Em outras palavras, é fundamental pensar uma educação que seja mediatizada primando, conforme revela Freire (1987) pela libertação, pela superação das práticas de dominação, o que se constitui como uma educação libertadora. 
Em suma, pode-se considerar que a mediação como prática pedagógica, principalmente a partir das três concepções apresentadas possui procedimentos em comum, como revelam Santos e Rezende (2002, p. 5):

\begin{abstract}
pressupõe que a mediação pedagógica se realize pelo diálogo, pela troca de experiências e debate de questões de forma instigadora; pelo auxílio à seleção, organização e avaliação de informações; cooperação entre os participantes; enfim, pelo desenvolvimento de uma ação educativa que promova a construção ativa do conhecimento pelo aluno, por meio do inter-relacionamento entre as pessoas, visando à apropriação da história e da cultura.
\end{abstract}

Diante da citação, entendemos que algumas terminologias são inerentes as percepções dos três estudiosos (Piaget, Vygotsky e Paulo Freire), tais como: diálogo, experiência, debate, construção, conhecimento, inter-relacionamento (interação, cooperação, etc.), apropriação, história e cultura. Portanto, percebemos que essa proposta de mediação a partir de um arrazoado das concepções dos três estudiosos pode ser aplicada em diversos ambientes, como a escola, a universidade e a biblioteca. O presente trabalho propõe uma reflexão sobre a mediação na biblioteca escolar, com vistas a percebê-la como instrumento de prática de mediação informacional e pedagógica.

\title{
4 Discurso aplicativo da mediação da informação na biblioteca escolar: perspectivas implícitas e explícitas
}

Como discutido no tópico anterior, o reconhecimento da mediação como fundamento de uma prática pedagógica, permite pensar uma contigüidade aplicativa com a biblioteca escolar, uma vez que é um centro de informação que também atua a partir de práticas informativo-pedagógicas, o que demanda uma construção mediacional. A mediação da informação pode ser vista a partir de várias perspectivas históricas, de construção de sentidos e de conhecimento, a saber:

a) "[...] a mediação da informação é um processo histórico-social. O momento em que se concretiza não é um recorte de tempo estático e dissociado de seu entorno. Ao contrário: resulta da relação dos sujeitos com o mundo.”. (ALMEIDA JÚNIOR, 2009, p.93);

b) Essa relação perpassa pelo processo de construção do conhecimento no qual os sujeitos interagem entre si e com as informações, processando-as para a partir de suas 
possibilidades cognitivas, se apropriarem do conteúdo quando ao final do processo um novo conhecimento é gerado e comunicado. (GOMES, 2008);

c) A mediação da informação é uma linha de pesquisa que propõe atividades de interferência que vão além da relação usuário/informação. Essas atividades perpassam por todo o fazer biblioteconômico, enfocando práticas que tornem o trabalho do bibliotecário, neste contexto entendido como um mediador subjetivo. Trabalho esse que configura a biblioteca escolar como um espaço intersubjetivo no compartilhamento de informação. (SANCHES; RIO, 2010).

Partindo dessas percepções o presente estudo estabelece perspectivas de mediação da informação na biblioteca escolar. Para tanto, toma como base o conceito de mediação da informação de Almeida Júnior (2009) que ocorre no espaço da biblioteca escolar nas duas modalidades já expostas: Mediação implícita e Mediação explícita.

\subsection{A mediação implícita na biblioteca escolar: reflexões no âmbito da sinalização, formação e desenvolvimento do acervo e organização/representação da informação}

É preciso ponderar que a organização das bibliotecas, em caráter geral, obedece a um instrumento padronizado, possibilitando estímulos para mediação que pode ser aplicado tanto as bibliotecas escolares, quanto as demais bibliotecas precisam organizar o seu acervo. Pensar a mediação implícita na biblioteca escolar requer observar um conjunto de fenômenos organizacionais que a norteiam, quais sejam: a sinalização externa/interna da biblioteca; a formação e desenvolvimento do acervo; a representação da informação, especialmente através de classificações bibliográficas e o uso das fontes de informação para incentivo à leitura e pesquisa no âmbito da comunidade escolar.

Desse modo, é pertinente atentar para o fato de que o bibliotecário se situa como instrumento humano de crucial relevância para promover a mediação implícita na biblioteca escolar. Entendemos que as perspectivas de organização da biblioteca escolar merecem uma abordagem mais detida. 
4.1.1 A sinalização da biblioteca escolar: subsídios externos e internos para sua valorização diante dos usuários da informação

É comum observar a sinalização apenas como acessório estético na biblioteca escolar. Porém, acreditamos que a sinalização tem uma produção mais ampla do ponto de vista organizacional e informacional. Neste caso, é preciso pensar não somente na estética da biblioteca escolar, mas principalmente na imagem social promovida pela biblioteca escolar, sendo esta imagem concebida não simplesmente como aquilo que a biblioteca escolar faz ou tenciona fazer, mas aquilo que o usuário constrói a partir das ações de sinalização da biblioteca escolar.

Esse discurso de imagem é pertinente para analisar a sinalização da biblioteca escolar, pois qualquer instrumento de uso coletivo e materialmente construído necessita de uma sinalização, como a sinalização do trânsito, sinalização de ruas/avenidas/estradas, sinalização de empresas, escolas, universidades, entre outros.

Isso significa dizer que a sinalização da biblioteca escolar deve ser estabelecida incentivando à autonomia do usuário da informação. Para tanto, é preciso ponderar essa sinalização em níveis. Em caráter geral, podemos conceber dois níveis de sinalização: externo e interno.

Pimentel, Bernardes e Santana (2007, p. 31) elegem que a:

a) sinalização externa:

- facilita o acesso à biblioteca e assinala a importância concedida a ela no conjunto das instalações;

b) sinalização interna - de recepção:

- deve estar próxima à entrada e orientar os alunos dentro da biblioteca. Pode conter todas as informações dos serviços oferecidos pela biblioteca, como: empréstimo de livros, reforço escolar, hora do conto, horário de funcionamento, normas de uso, documentos necessários para inscrição ou cadastro etc.;

c) sinalização de uso do espaço:

- deve sinalizar os espaços de atividades da biblioteca, como estudo individual, estudo em grupo, mural interativo, mural de informações, atendimento, catálogo etc.;

d) sinalização temática das estantes:

- cada estante deve ter, em local de fácil visualização, a relação dos assuntos pelos quais foram distribuídos os livros. Alguns destaques ajudam na localização dos livros mais procurados, por exemplo: literatura brasileira, literatura infantil, obras de referência.

Entendemos que a sinalização da biblioteca em seu sentido externo se estabelece como elemento estratégico para localização e acesso as instalações. É pertinente que a biblioteca possua uma 'centralidade territorial' no espaço da escola, de sorte que a sinalização externa 
possa ser mais clara, objetiva e atrativa e sem muitos custos financeiros. No caso das bibliotecas escolares localizadas em espaços obscuros da escola, é preciso pensar em uma sinalização mais coordenada diante de todo o espaço da escola para atrair o usuário por meio de sinais (cartazes, textos, murais, etc.) que simbolizem a atuação da biblioteca escolar.

O ideal para uma sinalização externa é despertar a curiosidade no usuário mostrando que a biblioteca escolar se constitui em um conjunto de atividades de informação que fazem parte do cotidiano dos usuários e que estes devem acompanhar o processo, visando participar para a construção de uma biblioteca ativa e eficaz.

Já a sinalização interna, embora seja mais específica em termos territoriais, possui maior complexidade em face de suas particularidades, principalmente no contexto da recepção, do espaço e das estantes. A sinalização interna contempla na orientação ao usuário sobre os espaços internos que compõem a biblioteca, assim como estimulam o usuário a se situar no ambiente, seja na recepção, seja com relação aos serviços e espaços que utilizada ou pretende utilizar ou com relação a sua busca nas estantes.

Observa-se que a sinalização interna pode contribuir para o processo de seleção do acervo, recuperação da informação e uso das fontes de informação, principalmente por meio de mensagens referentes aos conteúdos do acervo de cada estante (enfatizando temáticas/assuntos e até autores) e no espaço da biblioteca de forma geral. Ressaltando que aqui entendemos a recuperação de informação como recuperação de documentos. (CAPURRO, 2007).

Concebendo um arrazoado das duas sinalizações, a própria biblioteca pode consultar aos usuários sobre como elaborar a sinalização permitindo uma construção sócio-interativa.

Em outras palavras, essa sinalização externa seria uma forma de pensar, como afirmam Silva e Ribeiro (2002) o significado de informação que desloca o conceito físico de informação (centrado em Shannon e Weaver) para o sócio-cognitivo, pois o usuário passa a ter papel decisivo nas tomadas de decisão.

Isso significa dizer que o ideário de informação de Shannon e Weaver está centrado no processo técnico, semântico (objetivista) e pragmático de transmissão (procedimento), sendo os processos de acesso, uso e apropriação da informação relegados a um plano inferior, embora não possamos deixar de destacar a concepção de eficácia na transmissão desenvolvida pelos estudiosos supramencionados, mas que está eminentemente ligada a transmissão da 
informação em si (a eficácia da transmissão) e não aos processos de mediação, acesso, uso e apropriação da informação pelo usuário/receptor, o que inibe a proposição de múltiplas possibilidades de acesso à informação ou interação entre a biblioteca escolar e o usuário.

Carvalho Silva e Freire (2012, p. 20) revelam com relação a Shannon e Weaver que os "os autores priorizam a noção de linearidade e objetividade no processo comunicacional em detrimento da subjetividade e das diversas formas de interpretação na comunicação."

Podemos perceber que pensar qualquer perspectiva de mediação na biblioteca escolar (ou qualquer outro tipo de centro de informação) demanda um olhar plural no que toca as relações entre biblioteca escolar, bibliotecário e usuário, sendo esses três 'seres', elementos fundamentais para múltiplas possibilidades de construção da informação.

Assim, é possível afirmar que a sinalização, seja de qual tipo for, implica em convite que supere a concepção de linearidade de transmissão da informação de Shannon e Weaver oferecendo e estimulando ao usuário múltiplos subsídios de acesso, uso e apropriação da informação a partir de uma interação com a biblioteca escolar e seus profissionais, o que delibera por uma construção intersubjetiva de informação, já que não é a biblioteca escolar ou o bibliotecário que fornecem informação ao usuário, mas partir de uma construção coletiva entre biblioteca, bibliotecário e usuário, este último deve conceber autonomia para definir a informação mais pertinente para satisfação de suas necessidades.

Portanto, a sinalização da biblioteca escolar prima pela subjetividade e supera a linearidade quando é construída com o usuário se configurando em um diálogo aberto entre a biblioteca escolar e os usuários em um procedimento de proposição mútua da sinalização, assim como a biblioteca deve acatar sugestões, intervenções e interferências dos usuários).

\subsubsection{A formação e desenvolvimento do acervo: processos aplicados a biblioteca escolar}

Os estudos sobre desenvolvimento do acervo (ou de coleções) na Biblioteconomia tem sido contemplado em muitas disciplinas dos cursos de graduação. Todavia, é pertinente atentar para o fato de que as pesquisas sobre desenvolvimento do acervo tem se dado de forma muito incipiente, o que desfavorece um pensamento mais amplo sobre o acervo de um centro de informação e suas possibilidades de ação no âmbito da(s) comunidade(s). 
Um dos poucos pesquisadores nacionais sobre a temática desenvolvimento do acervo é Waldomiro Vergueiro (1989) que afirma que o desenvolvimento do acervo insere os seguintes processos, quais sejam:

a) Seleção - uma técnica especializada, fornecida por conhecimento e experiência, criticamente testada e acompanhado princípios gerais;

b) Aquisição - o papel da aquisição, no processo, constitui-se em localizar e, posteriormente, assegurar a posse, para a biblioteca, daqueles materiais que foram definidos, pela seleção como de interesse;

c) Desbastamento - essa expressão é muito mais ampla que o simples expurgo de materiais (embora, na realidade, chegue a abrangê-lo);

d) Descarte - retirada definitiva do acervo da biblioteca de materiais repetidos, com pouco uso ou danificados;

e) Avaliação - a avaliação permitirá ao bibliotecário verificar as se etapas anteriores do processo, do estudo da comunidade ao desbastamento, estão sendo realizadas de forma coerente;

f) Conservação - o acervo deve ser restaurado para poder continuar a prestar a comunidade o mesmo nível de serviço.

Entendemos que a biblioteca é uma instituição milenar a qual ao longo da sua história constituiu uma variedade de suportes para registrar o conhecimento. Com o avanço das tecnologias de informação a biblioteca trouxe uma diversidade ainda maior de suportes para a informação registrada, pois, conforme Le Coadic (1996) não há mais distância que seja obstáculo à velocidade, nenhuma fronteira detém a informação.

Com relação a aplicação de cada ponto a biblioteca escolar compreendemos, em primeiro lugar, que a coleção da biblioteca não pode ser reunida aleatoriamente, haja vista que precisa ser um recurso didático eficiente e eficaz nas escolas. $\mathrm{O}$ acervo precisa ser formado e desenvolvido com critérios levando-se em conta o Projeto Político Pedagógico da escola, em função das propostas curriculares de cada área oferecendo materiais de consulta, acesso a internet, para garantir que os alunos utilizem esse tipo de recurso, livros para empréstimo domiciliar e periódicos. 
Em segundo lugar, verificamos que a aquisição é um dos pontos chaves para a formação e desenvolvimento do acervo na biblioteca. Para tanto, é fundamental que a biblioteca escolar estabeleça alguns critérios para composição/aquisição do seu acervo, tais como: elaboração de campanhas para arrecadação do acervo, de sorte que é uma forma de atrair o usuário para desenvolver em caráter coletivo ações da biblioteca possibilitando uma autonomia mais ampla da comunidade escolar interferindo nos rumos da biblioteca; a biblioteca escolar necessita fundamentalmente de estar inserida no discurso da sociedade em rede (CASTELLS, 1999), visando a constituição de redes sociais (MARTELETO; TOMÁEL, 2005) ou redes de conhecimento (TOMÁEL, 2008) que permitem os contatos e as interações com outras bibliotecas escolares, de modo que possam trocar ou doar materiais a fim de renovar seu acervo, de acordo com as necessidades específicas de cada comunidade escolar; no caso de escolas públicas, o uso de recursos como o Programa Dinheiro Direto na Escola (PDDE) para compra de materiais específicos que podem ser sugeridos pelos próprios professores.

Em terceiro lugar, o desbastamento e o descarte possuem grande contigüidade no ambiente da biblioteca escolar, especialmente, em escolas públicas, pelo fato de que muitos materiais são comprados de forma aleatória pelo governo Federal, Estadual ou Municipal, o que inibe pensar em um desenvolvimento do acervo mais planejado. Ressaltando que alguns materiais chegam em quantidades desnecessárias, como obras de referências - dicionários, enciclopédias que tomam espaço demasiado nas estantes da biblioteca prejudicando um efetivo aproveitamento do acervo e do espaço. Assim, é pertinente pensar em estratégias de desbastamento e descarte, além de permutas que permitam tornar o espaço da biblioteca mais produtivo.

Em quarto e último lugar, percebemos a relevância da avaliação na biblioteca escolar precisamente para perceber o que pode e deve ser selecionado, adquirido, desbastado, descartado e conservado ou passível de uma política de conservação. Contudo, todo esse processo de formação e desenvolvimento do acervo é viabilizado com as práticas dos estudos de comunidades e usuários, pois as decisões tomadas com relação ao planejamento da biblioteca escolar devem ter a participação do usuário, tanto no desenvolvimento do acervo, quanto dos serviços. 
4.1.3 Organização e representação da informação: processos técnicos aplicados a biblioteca escolar

Organizar e representar a informação em bibliotecas é uma atividade que está intrinsecamente relacionada a vários fundamentos, como o estudo de comunidades/usuários, assim como a formação e desenvolvimento do acervo.

Pimentel, Bernardes e Santana (2007) elencam etapas que constituem a organização/representação da informação na biblioteca escolar, tais como: seleção do acervo (aproveitar o material que será utilizado; identificação (uso do carimbo da biblioteca para definir que aquele material é pertencente aquela instituição); registro (serve para saber quantos livros existe na biblioteca e para identificar o livro na hora de empréstimo, o que demanda o uso do carimbo e de um livro de registro ou tombo); o uso de um sistema de recuperação de informação ou software de gerenciamento do acervo (é fundamental para registrar o acervo de forma automática) e classificação (é útil para localizar um livro em uma coleção; retirar um livro para consulta com rapidez; devolver um livro à coleção com rapidez; inserir novo livro aos já existentes na coleção, sem que esses percam a sua ordem lógica).

É pertinente observar quanto ao sistema de recuperação de informação que deve compor o registro de elementos básicos do acervo, como autor, título, edição, editora, local, ISBN, entre outros. Destacamos alguns sistemas gratuitos que podem ser utilizados em bibliotecas escolares: PHL8, Bib Livre, MiniBiblio, etc.

No que se refere a classificação para bibliotecas escolares algumas são muito utilizadas, como a classificação por assunto que tem como vantagem valorizar o conteúdo do acervo da biblioteca, mas tem como desvantagem a imprecisão no processo de busca e recuperação de informação; a classificação por cores em que recomendamos a sua utilização em bibliotecas infantis ou em uma seção da biblioteca escolar que componha apenas acervo infantil, ou seja, acervo adaptado para crianças até aproximadamente 7 anos de idade ${ }^{1}$; o uso da classificação decimal (CDD, CDU), além de tabelas como Cutter (útil para qualquer público, inclusive o infantil) apresentando a perspectiva de quando o usuário, principalmente

\footnotetext{
${ }^{1}$ É preciso atentar para o fato de que muitas bibliotecas escolares são compostas de uma comunidade diversa que pode incluir crianças de 7 a 14 anos, Educação de Jovens e Adultos (EJA), além dos professores e funcionários (público adulto), comunidade externa (pais, familiares, moradores adjacentes da escola). Isso significa que a classificação pode ser pensada a partir de formas específicas de valorizar cada público, conforme suas particularidades.
} 
o estudante, lidar com outros centros de informação como, por exemplo, uma biblioteca universitária, possa ter constituído uma intimidade com o funcionamento do centro de informação, sabendo quais são os instrumentos elaborados para representação e recuperação da informação.

Vianna (2008, p.45) assevera que "os sistemas de classificação, os códigos de catalogação e os formatos de intercâmbio bibliográfico [...] constituem os instrumentos básicos que bibliotecários do mundo inteiro costumam utilizar para organizar os acervos da biblioteca".

É importante que mesmo em bibliotecas escolares consideradas com acervo pequeno esse processo de organização/representação da informação possa ser elaborado como uma maneira de familiarizar o aluno com procedimentos padrões que possa verificar também em outros tipos de bibliotecas.

\subsection{A mediação explícita aplicada a biblioteca escolar: o desiderato social dos serviços da biblioteca escolar e usuários}

A Sociedade da Informação é caracterizada pela multiplicidade de informação existente. Neste cenário é necessário que o indivíduo seja capaz de saber reconhecer a sua necessidade de informação, saber avaliar as fontes de informações e principalmente interpretar as informações colhidas nos diferentes suportes. Essa competência poderá ser adquirida pelo aluno se a biblioteca da escola mediar serviços que ensinam esses alunos a buscar a informação nas diversificadas fontes possuindo habilidades para manuseá-las.

\footnotetext{
A busca pela formação de cidadãos competentes no uso da informação deve ser iniciada na pré-escola, acentuando-se no período do ensino fundamental, fase introdutória dos educandos ao ambiente da biblioteca escolar e com as fontes de informação, sendo o período propício para a realização da instrução da competência em informação. (MATA; SILVA, 2008)
}

É preciso considerar que a biblioteca escolar é um dos primeiros instrumentos pedagógicos de acesso à informação (ou pelo menos deveria ser), principalmente para os estudantes das séries iniciais (ensino fundamental I e II) que deve estimular o contato e uso das fontes de informação, além do incentivo à leitura e a pesquisa.

De acordo com Sousa (2008) o entendimento entre escola e biblioteca e, principalmente, entre professor e bibliotecário escolar, promove a conquista dos leitores: 
crianças e jovens que serão estes, embriões dos usuários permanentes de bibliotecas, centros de informação e informação virtual.

Assim, podemos pensar a mediação da informação como instrumento pedagógico fundamental que através dos serviços construídos junto a comunidade escolar vislumbra possibilidades para a efetivação de uma autonomia da informação por parte dos usuários, sendo alunos, professores, usuários, além da comunidade externa.

Segundo a UNESCO (1999) a biblioteca escolar tem a missão de "promover serviços de apoio à aprendizagem e livros aos membros da comunidade escolar, oferecendo-lhes a possibilidade de se tornarem pensadores críticos e efetivos usuários da informação, em todos os formatos e meios." Mata e Silva (2008) esclarecem que a missão da biblioteca escolar pressupõe assistência ao aluno em relação à sua aprendizagem, por isso deve-se disponibilizar materiais em diversos suportes para que os alunos conheçam as diversas fontes de informação e adquiram habilidades como a localização, a avaliação e a utilização, de modo que satisfaça suas necessidades e resolva como argumentam Wersig (1993) e Saracevic (1996) problemas de informação.

Diante do exposto, o bibliotecário precisa exercer a sua função de mediador a partir dos serviços de informação estimulando aos usuários o desenvolvimento de habilidades necessárias para uma autonomia e competência em informação configurando procedimentos de mediação explícita.

4.2.1 Entre o cotidiano e a realidade disciplinar da escola/biblioteca escolar: mediação da informação para leitura

Quando se fala em mediação da leitura é muito comum remeter todo o processo a responsabilidade a escola. Todavia, é preciso considerar que a mediação é um ato de construção de sentido de vida. Logo, a escola não pode e nem deve ser a única mediadora da leitura. Acreditamos que família (em primeiro lugar), professores, bibliotecários, amigos, escritores, pesquisadores, editores, críticos literários, jornalistas, livreiros, entre outros podem se constituir como mediadores para a leitura.

Considerando o âmbito da escola entendemos a biblioteca como elemento crucial de mediação para a leitura, assim como o bibliotecário e os professores são sujeitos centrais 
nesse processo de mediação. Com efeito, percebemos que para um bibliotecário ou professor se constituir como mediador para leitura é preciso que goste de ler. Aqui entendemos leitura não apenas como o ato da palavra escrita ou oral, mas a leitura de mundo com suas finalidades de estimular o pensamento crítico e multiplamente interpretativo. Como nos revela Paulo Freire (1988) que a leitura do mundo precede sempre a leitura da palavra.

Dessa maneira, a mediação para a leitura a partir da biblioteca escolar deve estimular o usuário a interpretar o seu cotidiano, as suas condições e perspectivas de vida, pois uma leitura distante da realidade cotidiana pode se configurar como algo vazio e inibidor da construção de sentidos. Entendemos que a biblioteca escolar, por meio do bibliotecário e professores, pode conceber um processo de mediação para leitura a partir de dois contextos:

a) O primeiro é a mediação da leitura de mundo que aborda temáticas diversas do cotidiano dos usuários (relações familiares, valores humanos - amor, carinho, amizade - consciência ambiental, incentivo as atividades profissionais e escolares, saúde, prática artística, esportes, cultura, etc.) que pode ser contemplada por meio de atividades culturais (teatro, música, dança, desenho, pintura, contação de histórias, etc.), além dos serviços de informação utilitária (será explicitado mais adiante);

b) O segundo é a mediação da leitura referente as disciplinas escolares, como a literatura, história, geografia, português, matemática, etc.

Essas duas propostas de mediação são complementares e não excludentes, pois com o estímulo à leitura de mundo o usuário, principalmente o estudante das séries iniciais pode engendrar subsídios intelectivos para pensar a realidade que o cerca, enquanto o estímulo à leitura disciplinar pode estimular o usuário a pensar os desafios escolares e profissionais de sua trajetória.

Em ambos os casos, leitura de mundo e leitura disciplinar contribui para o cotidiano do usuário promovendo condições para concepção de uma cultura de informação pelo usuário, inclusive a partir do reconhecimento de que a biblioteca é um espaço para construção de conhecimentos ligados a sua realidade social e cotidiana e não apenas um espaço que designa de forma unilateral e arbitrária o que o usuário deve 'ler'.

Enfim, a mediação para leitura pode ser pensada, por um lado, a partir do viés construtivista (PIAGET, 1978) em que o sujeito está em permanente processo de construção do conhecimento, além do que a leitura, seja de mundo, seja disciplinar, não deve ser pautada 
com arbitrariedade, mas deve primar pela satisfação das necessidades cotidianas dos usuários e, por outro lado, pode ser constituída a partir de uma perspectiva sócio-histórica/sóciointeracionista de Vygotsky (1998), de sorte que cumpre a biblioteca escolar, incentivar o gosto pela leitura com atividades que primem pela composição das atividades históricas, culturais, sociais e psicológicas do ser (usuários), valorizando a internalização das ideias pelos usuários com vistas a apropriação e aprendizagem a partir de uma interação sem hierarquias.

4.2.2 Mediação da informação para pesquisa: estratégias para docentes e discentes

A mediação para a pesquisa pode ser concebida como atributo complementar ou até mesmo unificado a mediação para leitura, pois em ambos os casos, a preocupação deve estar centrada na construção de conhecimento do usuário. A diferença é que na leitura, seja de mundo, seja disciplinar, o usuário insere passos considerados mais embrionários, enquanto na pesquisa o usuário já mostra um grau de maturidade mais efeito, pois além de leitura de mundo ainda pode demonstrar uma contribuição inovadora, tanto individual, quanto coletiva.

Quando falamos em mediação da informação para a pesquisa estamos observando duas realidades básicas dos usuários: realidade docente e discente em que há uma profunda relação nesse processo de mediação da pesquisa, mas também há suas particularidades.

Pedro Demo (1996) em seu livro educar pela pesquisa destaca alguns fundamentos que permitem analisar possibilidades de mediação para a pesquisa considerando previamente que a educação pela pesquisa só é possível através de 2 (dois) aspectos: o primeiro é que o professor precisa ser um pesquisador e aplique isso no seu cotidiano e o segundo é que o aluno deve deixar de ser um simples objeto para ser companheiro de trabalho. O autor destaca ainda fundamentos que valorizam as competências dos alunos e do professor para pesquisa, conforme indica o quadro a seguir: 
Quadro 1: Competências de educação para pesquisa

\begin{tabular}{|c|c|}
\hline Pesquisa no aluno & Pesquisa no professor \\
\hline $\begin{array}{l}\text { 1. A escola deve ser o ambiente criativo por } \\
\text { excelência, onde o aluno tem participação ativa e } \\
\text { motivação constante, e não um ambiente repressor que } \\
\text { cultiva apena a disciplina. Favorecer o lúdico. }\end{array}$ & $\begin{array}{l}\text { 1. Construir um projeto } \\
\text { pedagógico próprio que deve } \\
\text { estar em atualização permanente } \\
\text { e ter compromisso com o } \\
\text { desempenho do aluno }\end{array}$ \\
\hline $\begin{array}{l}\text { 2. Valorizar o trabalho em equipe, buscando o equilíbrio } \\
\text { entre individualidade e solidariedade. }\end{array}$ & $\begin{array}{l}\text { 2. Construir textos científicos e } \\
\text { pedagógicos próprios, com } \\
\text { fundamentação teórica }\end{array}$ \\
\hline $\begin{array}{l}\text { 3. Incentivar o aluno a ter iniciativa na busca de material } \\
\text { para pesquisa e combater a receita pronta. }\end{array}$ & $\begin{array}{l}\text { 3. Refazer o material didático, e } \\
\text { testá-lo antes de levar aos } \\
\text { alunos, seja teórico ou prático. }\end{array}$ \\
\hline $\begin{array}{l}\text { 4. Motivar para o aluno conceber suas próprias } \\
\text { interpretações, reelaborando-as. Interpretar o material } \\
\text { pesquisado. Passar de atitude passiva para atitude } \\
\text { crítica. }\end{array}$ & $\begin{array}{l}\text { 4. Inovar na prática didática, } \\
\text { lutando contra a aula } \\
\text { reproduzida e copiada, e contra } \\
\text { a postura passiva dos alunos. }\end{array}$ \\
\hline $\begin{array}{l}\text { 5. Reconstruir a partir co conhecimento prévio, } \\
\text { acrescentando o conhecimento disponível, } \\
\text { elaborando textos próprios. }\end{array}$ & $\begin{array}{l}\text { 5. Recuperar constantemente a } \\
\text { competência através da } \\
\text { pesquisa, de cursos de } \\
\text { atualização, de eventos, pós- } \\
\text { graduação, etc. }\end{array}$ \\
\hline $\begin{array}{l}\text { 6. Material didático: motivações lúdicas, gosto } \\
\text { pela leitura, uso de computador, TV, DVD, apoio } \\
\text { dos pais, uso intensivo do tempo escolar }\end{array}$ & \\
\hline $\begin{array}{l}\text { 7. Cuidados propedêuticos (iniciais, introdutórios } \\
\text { relativos ao Ensino Fundamental. }\end{array}$ & \\
\hline $\begin{array}{l}\text { 8. Reorganização curricular } \\
\text { - Currículo extensivo é sinônimo de educação bancária } \\
\text { - Currículo intensivo é sinônimo de pesquisa, pois: } \\
\text { aprofunda-se o mesmo através de temas e constrói-se } \\
\text { uma visão geral e não compartimentalizada. } \\
\text { Preferência por aulas mais longas proporcionando } \\
\text { ambiente próprio para pesquisa e leitura, análise, } \\
\text { discussões, preparação do trabalho. Flexibilização do } \\
\text { currículo. Levar em consideração os ritmos individuais } \\
\text { e próprios, combater o fracasso. }\end{array}$ & \\
\hline $\begin{array}{l}\text { 9. Avaliação: utilizar formas alternativas e constantes, } \\
\text { como debates, argumentações orais e escritas, } \\
\text { participação }\end{array}$ & \\
\hline
\end{tabular}

Fonte: Adaptado de Pedro Demo (1996)

Diante do quadro apresentado, podemos inserir a biblioteca escolar no âmbito da educação para a pesquisa por ser um espaço de prática pedagógico-informacional percebendo 
possibilidades diversas de mediação. Todavia, é preciso compreender o(s) significado(s) do termo pesquisa a fim de refletir no âmbito da mediação da informação. Assim, entendendo a pesquisa como uma atividade de aproximação sucessiva da realidade que nunca se esgota, fazendo uma combinação particular entre teoria e dados (MINAYO, 1993, p. 23) e "procedimento racional e sistemático que tem como objetivo proporcionar respostas aos problemas que são propostos". (GIL, 1991, p. 19) observamos que a mediação da informação da biblioteca escolar deve estimular a prática da investigação sistemática e permanente por parte de docentes e discentes, com vistas a resolução de problemas, tanto do cotidiano da escola, quanto da realidade social.

Com relação a mediação da biblioteca escolar com o professor apresentamos algumas percepções que podem ser aplicadas por meio de práticas interativas e socialmente construídas.

Em primeira instância, a biblioteca pode estimular os professores no que se refere a participação de eventos e produção de trabalhos técnicos e científicos (projetos, artigos, etc.) estimulando a qualificação profissional por meio de uma prática investigativa de pesquisa. Para tanto, a biblioteca pode elaborar um guia mostrando como elaborar artigos, projetos, monografias, assim como um guia de normalização que seja acessível ao público docente, visando estimular a prática da pesquisa.

Em segunda instância a biblioteca pode ainda conceber uma divulgação permanente de eventos, periódicos/revistas nas diversas áreas do conhecimento incentivando a produção/divulgação de textos.

Em terceiro lugar, a biblioteca pode estimular pesquisas que estejam relacionadas ao cotidiano da educação e do público docente/discente como forma de aprimorar as práticas do ensino e das atividades curriculares.

Em seguida, é possível ainda o incentivo da biblioteca no que tange a divulgação de editais públicos e privados que incentivem os docentes a desenvolverem propostas que contemplem suas atividades educativas, pois além de contribuir com o ensino, os alunos e a própria prática docente pode contribuir para a escola e a comunidade escolar de forma mais ampla.

Finalmente, a biblioteca pode elaborar juntamente com os docentes, eventos, palestras e cursos que abordem assuntos diversos do cotidiano dos docentes e da comunidade escolar, 
como saúde (higiene, prevenção de doenças, gravidez precoce, etc.); educação (vestibular, acesso a internet, estímulo a escrita e a leitura...); desenvolvimento sustentável (como aproveitar materiais recicláveis e como utilizar os recursos naturais e energéticos de forma equilibrada), cultura popular (expressões da cultura local, regional e nacional) e também relativo a discussão sobre metodologias e práticas para as disciplinas escolares que possam estimular o pensamento crítico quando as práticas curriculares, como Português (redação, interpretação de textos...); História (questões relativas a história local, regional, nacional e global); Geografia (questões de espaço, geopolítica, nações, territórios, relação entre homem e natureza, etc.); Matemática (por exemplo, aprimoramento das metodologias para ensino e aprendizagem na disciplina de forma dinâmica, observando o pensamento de especialistas e possivelmente chamando algum especialista para diálogo); Ciências/Biologia (estudos sobre a natureza em suas diversas nuances animais, vegetais e minerais).

Quanto aos alunos, é pertinente que a escola possa abrir um espaço mais amplo para a biblioteca, visando inseri-la como espaço de prática pedagógica e inseri-la de forma cotidiana nas ações curriculares, disciplinares e cotidianas da escola. Desse modo, é possível aproximar o diálogo entre biblioteca e usuário discente de forma mais eficiente e eficaz. Entendemos que além das atividades pedagógicas da biblioteca consideradas mais convencionais que podem estimular a leitura e a pesquisa por meio do lúdico, como contação de histórias, teatro, música, dança, etc. é pertinente que a biblioteca desenvolva um conjunto de atividades que estimulem a prática da pesquisa como serviços de alerta informais (exposições, palestras cursos) e formais (listas de novas aquisições) e ainda, assim como foi sugerido aos professores com relação as disciplinas a biblioteca também pode fazer com os usuários discentes.

4.2.3 Mediação da informação no contexto dos serviços: ênfase no serviço de referência, serviço de informação utilitária e o uso das tecnologias de informação e comunicação

Os serviços se constituem como um dos principais mecanismos para mediação da informação em um centro de informação, de sorte que se configura como uma proposta materializada e concreta que aproximam o centro de informação e o usuário. No presente estudo, elencamos alguns tipos de serviços fundamentais que podem ser desenvolvidos em uma biblioteca escolar para mediação, além dos já mencionados relativos à leitura e a 
pesquisa: serviços de referência (virtual e físico) e serviços de informação utilitária, além de serviços que contemplam o uso das tecnologias de informação e comunicação.

Serviços de referência: fundamentos básicos para mediação da informação na biblioteca escolar

A partir da necessidade que se estabelece da interação entre as atividades biblioteconômicas e os usuários de biblioteca escolar de maneira a ficar latente as atribuições de ampliar o acesso â informação remetemos ao serviço de referência.

A implantação do serviço de referência nas bibliotecas fez com que a sua estrutura e finalidade perante os usuários mudassem. Com esse serviço o profissional da informação passou a ser o mediador da informação contida nas bases de dados e fontes de informação para o usuário final. A base do serviço de referência e informação (SRI) é fundamentada em técnicas e princípios biblioteconômicos de longa data que resistem contra o tempo (MACEDO, 1999).

Na mediação explicita do SRI o bibliotecário escolar interage diretamente com o usuário. Macedo (1999) tem uma visão sobre o Serviço de Referência e Informação alertando que pode ser representado como o coração do sistema bibliotecário no qual é bombeado todo sangue informacional, o qual prévia e tecnicamente tratado irá prover aos usuários os pontos diversos de acesso à informação bibliográfica registrada.

Sanches e Rio (2010) nesse cenário do serviço de referência apresenta o papel do bibliotecário, que é um profissional que trabalha essencialmente com informação, está inserido e desempenha um papel construtivo no processo de mediação da informação na biblioteca, a saber: gerenciar o espaço de aquisição da informação estrategicamente por meio de técnicas e procedimentos de tratamento, organização e disseminação da informação, de maneira a proporcionar uma maior interação de sua comunidade usuária com o conhecimento socialmente produzido.

Isso significa dizer que o SRI compõe a base de atuação do bibliotecário e se constitui como fundamento técnico e pedagógico na biblioteca escolar. Figueiredo (1996) aponta um conjunto de tipologias de SRI's que podemos também aplicar nas bibliotecas escolares: 
1) Provisão de documentos: circulação, consulta, empréstimo entre bibliotecas, fornecimento de copias, entrega de material;

2) Provisão de auxilio bibliográfico: localização de material, verificação de referencias, levantamento bibliográfico em assuntos especializados;

3) Serviço de alerta: informais (exposições), formais (lista de novas aquisições);

4) Orientação ao usuário: consulta orientada, cursos de instrução Bibliográfica e assuntos diversos.

Diante das atribuições estabelecidas, observamos que o SRI é fundamental para a existência de qualquer biblioteca, inclusive a escolar, de modo que contempla as atribuições básicas e fundamentadas que uma biblioteca deve empreender em sua lógica de atuação pedagógica.

Vale destacar que é a partir da provisão de documentos, auxílio bibliográfico, serviço de alerta e orientação ao usuário que a mediação explícita ganha um corpus mais consistente em termos de ação da biblioteca escolar, relação com o usuário e possibilidades pedagógicas para apropriação da informação pelo usuário.

Serviços de informação utilitária: mediação entre biblioteca escolar e o cotidiano do usuário

O termo serviço de informação como é comumente chamado atualmente já fora denominado de serviço de informação para a comunidade. De acordo com Campello (1998, p.2) os serviços de informação utilitária "surgiram nos Estados Unidos e na Grã Bretanha na década de 60, influenciados pelo Manifesto da UNESCO para Bibliotecas Públicas”.

O serviço de informação utilitária surge para suprir uma grande lacuna de ação das bibliotecas: as ações voltadas para as necessidades do dia-a-dia dos usuários. Muitos usuários vão às bibliotecas para empréstimo de livros, leituras individuais ou em grupo. Porém, é muito difícil um usuário visitar uma biblioteca buscando informações sobre questões do dia-adia, como saúde (informações sobre saúde pública, higiene, prevenção de doenças, exercícios físicos, além de informações sobre hospitais públicos, particulares, postos de saúde, ambulâncias, farmácia popular, farmácias particulares, laboratórios, SUS, clínicas, unidades sanitárias, academias populares, academias particulares, etc.); Cultura e lazer (agenda cultural, calendário de eventos, cinemas, teatros, museus, centros e espaços culturais, salas de 
exposições, galerias de arte, estádios, órgãos ligados ao esporte); utilidade pública (assistência social ao menor, à mulher, ao idoso e etc., associações, assistência legal, juizados, tribunais, prisões, serviço de assistência gratuita, projetos públicos, serviços públicos de pagamento como gás, luz, água, telefone, etc., sindicatos, como tirar documentos de identidade, CPF, título de eleitor e outros, segurança, telefones úteis como bombeiros, emergências, polícia, imprensa local); Trabalho (agências de emprego e estágios, oportunidades de empregos, cursos e eventos de qualificação profissional, etc.), além de outros assuntos referentes a realidade cotidiana dos usuários.

Destarte, o serviço de informação utilitária insurge como uma efetiva proposta de mediação para a biblioteca escolar que pode contemplar várias questões do cotidiano. Além das questões já mencionadas no parágrafo anterior a biblioteca escolar pode conceber sua mediação como serviço de informação utilitária a partir da educação (informações sobre vestibular, cursos de qualificação, concursos, dicas de leituras, oferta de materiais bibliográficos em promoção nas livrarias e sebos, etc.); desenvolvimento sustentável (uso de materiais recicláveis, além do uso equilibrado dos recursos energéticos e naturais); etnicorraciais (cotidiano da cultura negra); entre outras.

Todavia, é evidente que essas sugestões são gerais, de modo que a biblioteca escolar necessita de interagir com seus usuários, visando reconhecer as necessidades cotidianas latentes entre seus usuários. Costa et al (1984) a prática desenvolvida a partir do serviço de informação utilitária não pode ser concebida de forma unilateral, mas deve ser participativa envolvendo várias categorias de pessoas, visando encontrar soluções para os seus problemas.

Essa interação e reconhecimento das necessidades dos usuários estimulam a autonomia do usuário em participar das ações da biblioteca, bem como justificam e ampliam sua existência e ações no âmbito da comunidade escolar. O serviço de informação utilitária estimula a mediação da informação por revelar a biblioteca escolar como espaço que escuta e dá voz aos seus usuários superando a percepção de que a biblioteca escolar é apenas o 'lugar do castigo' ou um 'depósito de livros'. 
O uso das tecnologias digitais para auxiliar na mediação da informação na biblioteca escolar

As tecnologias se configuram como efetivo instrumento de apoio a biblioteca escolar, especialmente no que toca a construção das mediações implícitas e explícitas. Porém, é comum observar um desprezo quando se fala de tecnologias digitais nas bibliotecas escolares, inclusive da própria Biblioteconomia. Silva (1995, p. 20-21) nos revela que:

Qual tem sido a preocupação dominante senão a problemática dos bancos de dados,
das redes de informação científica, dos centros ultra-informatizados de
documentação? Algo contra tais temáticas? De jeito nenhum! Alguma objeção no
que se refere ao desenvolvimento de recursos para a organização e a disseminação
da informação técnico-científica? De modo algum! Mas, diante de tal quadro, cabe a
formulação de certas questôes: quais são as principais dificuldades e limitaçães da
biblioteconomia brasileira? Qual o alcance, em termos de população atingida, de
todo aquele aparato informacional? Os bibliotecários e os autores da área
biblioteconômica conhecem os índices de analfabetismo e de fracasso escolar deste
país? Já ouviram falar de prioridade? Alguma vez já pronunciaram a expressão
"biblioteca escolar" sem demonstrar certa repugnância?

É pertinente atentar para fato de que o autor não despreza as tecnologias digitais, mas ao contrário, demonstra preocupação com a Biblioteconomia em não valorizar a sua aproximação com as bibliotecas escolares.

De certo modo, o autor elucida essa falta de aproximação quando interpela sobre "Qual o alcance, em termos de população atingida, de todo aquele aparato informacional? Os bibliotecários e os autores da área biblioteconômica conhecem os índices de analfabetismo e de fracasso escolar deste país? Já ouviram falar de prioridade? Alguma vez já pronunciaram a expressão "biblioteca escolar" sem demonstrar certa repugnância?" simplesmente faz uma provocação a área enfatizando que tecnologias digitais e questões sócio-educacionais estão intrinsecamente concatenas, sendo papel da Biblioteconomia lutar por essa aproximação e instigar essas práticas no âmbito da biblioteca escolar, seja na formação acadêmica, seja na prática profissional, seja na atuação dos órgãos de classes (conselho, associação e sindicato).

Com efeito, observamos que aproximar as tecnologias digitais das ações da biblioteca escolar é uma forma efetiva de pensar a mediação da informação, seja na mediação implícita ou explícita, como vimos nos tópicos anteriores.

E como pode ser pensada a mediação da informação na biblioteca escolar por meio das tecnologias digitais? Bicheri (2008, p. 123) nos mostra alguns artefatos: 
$\mathrm{Na}$ atualidade, com o crescente desenvolvimento da tecnologia, novos sistemas e fontes de informação são criados diariamente; vários recursos informacionais tradicionais (livros, revistas, dicionários, etc.) são disponibilizados em versão eletrônica. Fala-se em redes eletrônicas e suportes digitais facilitando o acesso a informação e obtenção do conhecimento. No rol dos recursos informacionais encontramos fóruns eletrônicos, conferências online, e-mails, lista de discussão, bates papos, rádios e televisões online, imagens de satélite em tempo real, etc.

Entendemos que as tecnologias digitais tem grande relevância para mediação da informação na biblioteca escolar. Porém, não devemos situar esses recursos apenas em sua disponibilização, mas em suas possibilidades de auxiliar na construção de conhecimento dos usuários. Isso significa dizer que as tecnologias podem ser utilizadas em todas as perspectivas implícitas e explícitas discutida neste estudo.

Na mediação implícita, as tecnologias tem importância no uso de um sistema de informação para registro dos documentos, na formação e desenvolvimento de um acervo virtual, no uso de fontes virtuais de informação, como sites, portais, blogs, etc., na própria sinalização da biblioteca escolar que pode contar com alguns programas de diagramação estratégicas, entre outros.

Já na mediação explícita, as tecnologias podem ser relevantes para estimular à leitura (leitura na internet de textos e assuntos diversos referentes as práticas curriculares ou a temáticas do cotidiano); pesquisa (pesquisa escolar nos sites de busca, portais, uso dos blogs como ferramenta de interação, além da construção de textos e/ou desenhos, pinturas artísticas no computador, uso dos conteúdos educacionais para estimular a pesquisa dos docentes e o aprimoramento das práticas curriculares, uso dos periódicos científicos para elaboração de projetos/propostas, etc.); serviços de referência (pesquisa on line no acervo da biblioteca, fornecimento de cópias on line através de links de sites ou instrumentos virtuais que contemplem as necessidades específicas dos usuários, serviço de alerta eletrônico que podem informais como a divulgação de novos serviços e produtos oferecidos pela biblioteca, divulgação de cursos oferecidos bem como promoções, através de boletins informativos on line ou alerta eletrônico no site da biblioteca ou formais como listas de novas aquisições on line, lista de duplicatas, formulário on line para solicitação de novas aquisições, formulário on line para solicitação de duplicatas); e serviços de informação utilitária (dicas virtuais de informações sobre saúde, educação, cultura e lazer, desenvolvimento sustentável, utilidade pública, uso das redes sociais...). 
Em suma, percebemos que as tecnologias digitais podem engendrar uma diversidade de subsídios para a mediação da informação na biblioteca escolar que se sintoniza em diversas atividades, quais sejam implícitas e explícitas.

\section{Considerações finais}

Os estudos sobre mediação da informação vem desempenhando importantes funções na Ciência da Informação considerando, inclusive, as realidades dos centros de informação, de sorte que a aproximação entre centro de informação e usuário pode ser pensada de uma forma eminentemente sócio-interacionista.

A biblioteca escolar, como espaço de prática pedagógica e construção do conhecimento necessita dos estudos sobre mediação da informação para aprimorar suas possibilidades de atuação, especialmente no que se refere às práticas da mediação implícita e explícita.

Consideramos que a mediação implícita da biblioteca escolar é constituída por um conjunto de atribuições que vão desde a sinalização até seu processo de organização/representação da informação, além da formação e desenvolvimento do acervo que favorece procedimentos para aproximar biblioteca escolar e usuário, sendo a primeira mais convidativa e o segundo concebendo uma postura mais autônoma.

Com relação a mediação explícita observamos um conjunto de fundamentos de leitura, pesquisa e serviços em que os estudos sobre mediação são fundamentais, uma vez que podem estimular a biblioteca escolar alçar melhor seu viés pedagógico se configurando como um espaço mais atrativo e menos burocrático/administrativo.

Observamos que a mediação da informação pode contribuir para a biblioteca escolar não somente como uma atribuição meramente pedagógica, mas também em vários aspectos que podem ser complementares, convergentes e/ou até divergentes: físico/digital; pedagógico/técnico; tecnológico/humano; ensino/pesquisa; docentes/discentes, tanto de forma individualizada, quanto coletiva.

Finalmente, esperamos que mediação da informação e biblioteca escolar possam se afunilar em escala efetiva promovendo, por um lado, contribuições as áreas de 
Biblioteconomia/Ciência da Informação e, por outro lado, contribuições para a comunidade escolar e a sociedade de forma mais ampla.

\section{Referências}

ALMEIDA JÚNIOR. O. F. Mediação da informação e múltiplas linguagens. Pesquisa brasileira em ciência da informação, Brasília, v.2, n.1, p.89-103, jan./dez. 2009.

BARRETO, A. A. Transferência da informação para o conhecimento. In: AQUINO, M. A. (Org). O campo da ciência da informação: gêneses, conexões e especificidades. João Pessoa: Editora Universitária/UFPB, 2002. p. 137-151.

BICHERI, A. L. A. D. O. A mediação do bibliotecário na pesquisa escolar face a crescente virtualização da informação. Marília, 2008. 198f. Dissertação (Mestrado em Ciência da Informação)-Universidade Estadual Paulista, 2008. Disponível em: $<$ http://www.marilia.unesp.br/Home/PosGraduacao/CienciadaInformacao/Dissertacoes/bicheri_alao_ me_mar.pdf $>$. Acesso em: 31 jul. 2012.

CAMPELLO, B. S. Fontes de informação utilitária em bibliotecas públicas. Revista de Biblioteconomia de Brasília, Brasília, v. 22, n. 1, jan./jun. 1998.

CAPURRO, R.; HJORLAND, B. O conceito de informação. Perspectivas em Ciência da Informação, Belo Horizonte, v.12, n.1, 2007.

CARVALHO SILVA, J. L. Perspectivas históricas da biblioteca escolar no Brasil e análise da Lei 12.244/10. Revista ACB: Biblioteconomia em Santa Catarina, Florianópolis, v. 16, n. 2, p. 489-517, jul./dez., 2011. Disponível em: <http://revista.acbsc.org.br/index.php/racb/article/viewFile/797/pdf_63 > Acesso em: 27 jan. 2012.

CARVALHO SILVA, J. L.; FREIRE, G. H. A. Um olhar sobre a origem da ciência da informação: indícios embrionários para sua caracterização identitária. Encontros Bibli: revista eletrônica de biblioteconomia e ciência da informação, Florianópolis, v. 17, n. 33, p. 1-29, jan./abr., 2012. Disponível em: $<\underline{\text { http://www.periodicos.ufsc.br/index.php/eb/article/view/1518-2924.2012v17n33p1/21708> }}$ Acesso em: 23 abr. 2012.

CASTELLS, M. A sociedade em rede. São Paulo: Paz e Terra, 1999. (A era da informação: economia, sociedade e cultura; v. 1.)

COSTA, M. N. M. et al. (Coord.). Biblioteca Pública como centro de informação utilitária: uma experiência no município de Santa Rita. Revista da Escola de Biblioteconomia da UFMG, Belo Horizonte, v. 13, n. 2, p. 179-195. 1984.

DEMO, P. Educar pela pesquisa. São Paulo: Autores Associados, 1996. 
FIGUEIREDO, N. M. Textos avançados em referência \& informação. São Paulo: Polis: Associação Paulista de Bibliotecários, 1996.

FREIRE, P. A importância do ato de ler: em três artigos que se completam. 22 ed. São Paulo: Cortez, 1988.

FREIRE, P. Pedagogia do oprimido. 17 ed. Rio de Janeiro: Paz e Terra, 1987.

GIL, A. C. Como elaborar projetos de pesquisa. 3. ed. São Paulo: Atlas, 1991.

GOMES, H. F. A mediação da informação, comunicação e educação na construção do conhecimento. DataGramaZero, Rio de Janeiro, v. 9, n. 1, 2008. Disponível em: <http://dgz.org.br.rt_01.htm>. Acesso em: 31 jul. 2012.

GOMES, H. F. A interligação entre comunicação e informação. DataGramaZero, Rio de Janeiro, v. 11, n. 3, jun. 2010a. Disponível em: <http://www.dgz.org.br/jun10/Art_03.htm>. Acesso em: 05 ago. 2012.

GOMES, H. F. Tendências de pesquisa sobre mediação, circulação e apropriação da informação no Brasil: estudo em periódicos e anais dos ENANCIB (2008-2009). Pesquisa brasileira em Ciência da Informação, Brasília, v. 3, n. 1, p.85-99, jan./dez. 2010b.

LE COADIC, Y. F. A ciência da informação. Brasília: Briquet de Lemos, 1996.

MALHEIRO, A.; RIBEIRO, F. Paradigmas, serviços e mediações em Ciência da Informação. Recife: Néctar, 2011.

MACEDO, N. D.; MODESTO, F. Do serviço de referência convencional. Revista Brasileira de Biblioteconomia e Documentação, São Paulo, v. 1, n. 1, 1999.

MATA, M. L.; SILVA, H. C. Biblioteca escolar e a aplicação da proposta da competência em informação no ensino fundamental. CRB-8 digital, São Paulo, v. 1, n. 3, p. 28-39, dez. 2008.

MARTELETO, R. M.; TOMÁEL, M. I. A metodologia de análise de redes sociais (ARS). In: VALEMTIM, M. L. P. (Org.). Métodos qualitativos de pesquisa em ciência da informação. São Paulo: Polis, 2005. p. 81-100.

MINAYO, M. C. S. O desafio do conhecimento. São Paulo: Hucitec, 1993.

PIAGET, J. Psicologia e epistemologia: por uma teoria do conhecimento. Rio de Janeiro: Forense, 1978.

PIAGET, J.; GARCIA, R. Psicogênese e história das ciências. Lisboa: Editora Dom Quixote, 1987.

PIMENTEL, G.; BERNARDES, L.; SANTANA, M. Biblioteca escolar. Brasília: Universidade de Brasília, 2007. 
SANCHES, G. A. R.; RIO, S. F. Mediação da informação no fazer bibliotecário no âmbito das ações culturais. InCid: Ciência da Informação e Documentação, Ribeirão Preto, v. 1, n. 2, p. 103-121, jul./dez., 2010.

SANTOS, H.; REZENDE, F. Formação, mediação e prática pedagógica do tutororientador em ambientes virtuais construtivistas de aprendizagem. Tecnologia Educacional, v. 31, n. 157/158, p.19-29, abr./set. 2002.

SARACEVIC, T. Ciência da informação: origem, evolução e relações. Perspectivas em Ciência da Informação, Belo Horizonte, v. 1, n. 1, p. 41-62, jan./ jun. 1996.

SILVA, A. M.; RIBEIRO, F. Das "ciências" documentais à ciência da informação. Porto: Afrontamento, 2002.

SILVA, W. C. Miséria da biblioteca escolar. São Paulo: Cortez, 1995.

SOUSA, M. I. J. Leitura escolarizada: entrecruzando olhares sobre a prática leitora na sala de aula e na biblioteca. In: ENCONTRO NACIONAL DE PESQUISA EM CIÊNCIA DA INFORMAÇÃO, 9., 2008, São Paulo. Anais.... São Paulo: USP, 2008. Disponível em: $<$ http://www.ancib.org.br/media/dissertacao/2135.pdf>. Acesso em: 25 jul. 2012.

SOUSA, M. T. Biblioteca escolar: usuário criativo é a realidade atual. CRB-8 Digital, São Paulo, v. 1, n. 3, dez. 2008. Disponível em:

$<$ http://revista.crb8.org.br/index.php/crb8digital/article/viewFile/21/21 >. Acesso em: 05 fev. 2012.

TOMAÉL, M. I. Redes de conhecimento. DataGramaZero, Rio de Janeiro, v. 9, n. 2, abr. 2008.

UNESCO. Manifesto da biblioteca escolar da IFLA/UNESCO. 1999. Disponível em: $<$ http://archive.ifla.org/VII/s11/pubs/portuguese-brazil.pdf $>$. Acesso em: 12 jun. 2012.

VERGUEIRO, W. Desenvolvimento de coleções. São Paulo: Polis/APB, 1989.

VIANNA, M. M. A organização da coleção. In: CAMPELO, B. (Org). A biblioteca escolar: temas para uma prática pedagógica. 2.ed. Belo Horizonte: Autêntica, 2008.

VYGOTSKY, L. S. A formação social da mente: o desenvolvimento dos processos psicológicos superiores. 6. ed. São Paulo: Martins Fontes, 1998.

WERSIG, G. Information science: the study of postmodern knowledge usage. Information Processing \& Management, v. 29, n. 2, p. 229-239, 1993. 